\title{
Technical and experimental errors in the spectrophotometric determination of oxygen saturation
}

\author{
R. G. FISH AND M. RADCLIFFE LEE \\ From the Pneumoconiosis Research Unit, Penarth, Glamorgan
}

SYNOPSIS The method of Deibler, Holmes, Campbell, and Gans (1959) is a quick, accurate, and reliable method for the determination of oxygen saturation. The results should be calibrated against those obtained by the Van Slyke method, and the setting, sensitivity, and reliability of the spectro- $\frac{\mathrm{O}}{3}$ photometer should be carefully established. This is especially necessary to meet the stringent requirements for accurate setting at the isobestic point $805 \mathrm{~m} \mu$. This method is superior to a method using saponin as a haemolytic agent and reading at only one wavelength.

Now that respiratory problems are being increasingly investigated in the laboratory there is need for a simple but reliable method for the determination of blood oxygen saturation based on standard equipment. This need has largely been met, for example, by Hickam and Frayser (1949), Wade, Bishop, Cumming, and Donald (1953), and Deibler et al. (1959). However, in attempting to set up a similar method we experienced a number of difficulties, not mentioned in the published texts, which are discussed below.

\section{METHODS}

The spectrophotometric method of Hickam and Frayser (1949) was used to begin with but that described by Deibler and her colleagues (1959) was later adopted. The results with both were compared against oxygen saturations determined by Van Slyke's constant volume method with which there should be close agreement.

In the method of Hickam and Frayser the blood is haemolysed with saponin and the optical density determined at $660 \mathrm{~m} \mu$. Fully oxygenated blood is treated in the same way and read at the same wavelength. The resulting optical density difference is converted into an oxygen difference in volumes per cent by use of the relationship:

Oxygen difference in vol. $\%=a$ (optical density difference) $+b$ where $a$ and $b$ are constants.

In the method of Deibler et al. blood samples are drawn into heparinized syringes, capped, and then stored in ice until analysed. A drop of mercury is added to each

Received for publication 8 March 1963

'Triton X 100 can be obtained from Messrs. V. A. Howe Ltd., 46 Pembridge Road, London, W.11. sample then $0.05 \mathrm{ml}$. of the Triton $\mathrm{X}^{1} 100$ solution $(33 \% \vec{\bullet}$ $\mathrm{v} / \mathrm{v}$ Triton $\mathrm{X} 100$ in 0.1 molar borax solution) is added to each millilitre of blood. The syringe is capped again and shaken gently by hand. An aliquot of the sample is transferred to a standard cuvette in which the light path is reduced to $1 \mathrm{~mm}$. Readings of optical density are then made, the first at $650 \mathrm{~m} \mu$ and then at $805 \mathrm{~m} \mu$ in a suitable spectrophotometer. The percentage saturation is then calculated from the following formula:-

Percentage saturation $=100\left[\frac{1-D^{650} / D^{805}-0.491}{3.738}\right]$

where $D^{650}=$ optical density at $650 \mathrm{~m} \mu$ and $D^{805}=$ optical density at $805 \mathrm{~m} \mu$

The figures 0.491 and 3.738 represent constants for the method.

To obtain a range of oxygen saturations human blood was equilibrated with appropriate gas mixtures in tonometers rotated in a water bath at $37^{\circ} \mathrm{C}$. A Unicam spectrophotometer (model SP 600) was used for the optical density determinations and the standard Van Slyke manometer for the gasometric determinations.

\section{DIFFICULTIES}

HAEMOLYSIS Saponin as used in Hickam and Frayser's method (1949) was found to be unsatisfactory since the efficacy of haemolysis and hence the 0 quantity required varies from one sample to another.

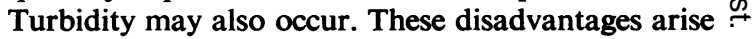
because saponin is not a pure chemical substance but $T$ a biological product containing variable amounts of $\frac{\vec{D}}{\mathbb{D}}$ the haemolytic substance. The use of Triton X 100 is a marked improvement; first it is of known chemical structure, secondly it is extremely active: for complete 
haemolysis only $0.05 \mathrm{ml}$. of Triton X 100 per millilitre of blood is necessary. Hence turbidity of the solution and dilution are not important factors, confirming the experience of Deibler et al.

HAEMOGLOBIN DETERMINATIONS Accurate determination of haemoglobin is necessary for conversion of oxygen capacity to saturation. The M.R.C. grey wedge photometer was not sufficiently accurate $(2 \%$ difference on the average between duplicates). Accordingly total haemoglobin was determined by conversion to cyanmethaemoglobin as described by Drabkin and Austin (1935-36). Duplicates then agreed to less than $1 \%$.

OPTICAL DENSITY DETERMINATION AT 650-660 M $\mu$ Readings of optical density are reliable at this wavelength as it is on a flat part of the characteristic absorption curves of the pigments. However, reading only at one wavelength, as in the method of Hickam and Frayser, did not eliminate the effects of interfering substances such as bilirubin and lipids. These authors claimed that there was little difficulty on this account but we believe it to be a common trouble at this wavelength.

OPTICAL DENSITY DETERMINATION AT $805 \mathrm{M} \mu$ It is essential that the isobestic point of haemoglobin and reduced haemoglobin $(805 \mathrm{~m} \mu)$ should be accurately given by the spectrophotometer. At this wavelength the absorption curve of oxyhaemoglobin undergoes an acute minimum; a shift in wavelength of 100 Angstrom units gives almost $10 \%$ change of transmission. On being set at $805 \mathrm{~m} \mu$ our instrument was about 100 Angstrom units out when checked by an $805 \mathrm{~m} \mu$ narrow band metal dielectric interference filter (Barr and Stroud). Checking with the didymium glass filter supplied with the instrument did not reveal this defect in setting. This filter checks the instrument throughout a wide range of wavelengths but is not sensitive enough to show small shifts of

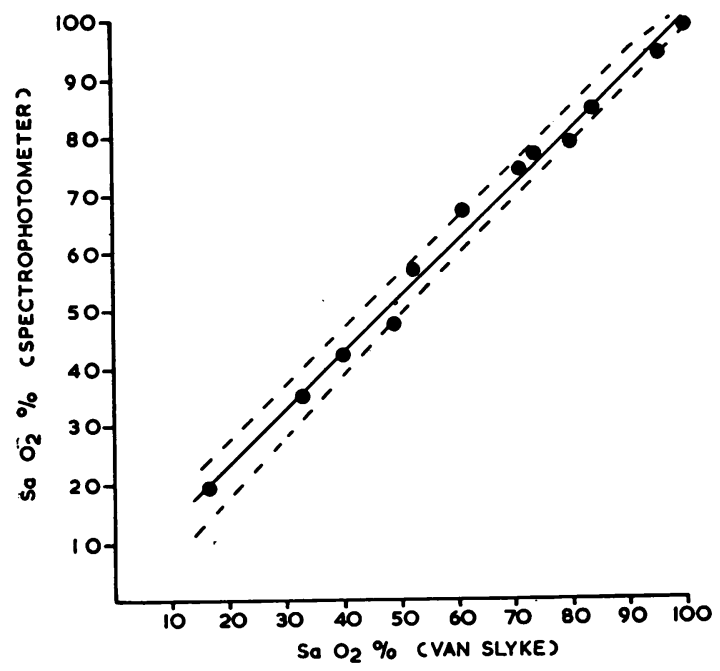

FIG. 1. Comparative determinations of oxygen saturation by manometric and spectrophotometric methods.

setting which become very important at the $805 \mathrm{~m} \mu$ minimum. Apart from the faulty setting our instrument showed a declining sensitivity over a period of time shown by the stringent requirements of the method of Deibler $e t$ al. and also by the need for a wider slit width to obtain a balance on 'check'. Moreover the micro-ammeter was excessively unstable on 'dark current'. Subsequently these deficiencies were corrected by the manufacturer and then replicable readings were obtained at $805 \mathrm{~m} \mu$.

\section{RESULTS}

The table summarizes a representative sample of results obtained by the spectrophotometric and gasometric methods.

Figure 1 represents the results of comparative determinations of the percentage oxygen saturation by the manometric and Deibler spectrophotometric

\section{TABLE}

COMPARISON OF RESULTS OBTAINED BY GASOMETRIC AND SPECTROPHOTOMETRIC METHODS

\begin{tabular}{|c|c|c|c|c|}
\hline Case No. & $\begin{array}{l}\text { Blood } O, \text { Capacity } \\
\text { (vol. \%, cyanide method) }\end{array}$ & $\begin{array}{l}\text { Ratio of D650/D805 } \\
\text { Optical Densities }\end{array}$ & $\begin{array}{l}\% \mathrm{O}_{2} \text { Saturation } \\
\text { (Deibler et al.) }\end{array}$ & $\begin{array}{l}\% \mathrm{O}_{2} \text { Saturation } \\
\text { (Van Slyke) }\end{array}$ \\
\hline $\begin{array}{r}1 \\
2 \\
3 \\
4 \\
5 \\
6 \\
7 \\
8 \\
9 \\
10 \\
11 \\
12\end{array}$ & $\begin{array}{l}21 \cdot 90 \\
19 \cdot 20 \\
22 \cdot 45 \\
20 \cdot 82 \\
27 \cdot 37 \\
25 \cdot 16 \\
20 \cdot 51 \\
27 \cdot 48 \\
18 \cdot 58 \\
18 \cdot 19 \\
16 \cdot 33 \\
21 \cdot 87\end{array}$ & $\begin{array}{l}3.533 \\
2.921 \\
2.666 \\
2.463 \\
2.112 \\
1.737 \\
1.447 \\
1.374 \\
1.290 \\
1.099 \\
0.762 \\
0.553\end{array}$ & $\begin{array}{l}18 \cdot 62 \\
35 \cdot 00 \\
41 \cdot 76 \\
47 \cdot 25 \\
56 \cdot 60 \\
66 \cdot 50 \\
74 \cdot 43 \\
76 \cdot 30 \\
78 \cdot 62 \\
83 \cdot 72 \\
95 \cdot 71 \\
98 \cdot 40\end{array}$ & $\begin{array}{r}16 \cdot 87 \\
33 \cdot 85 \\
40 \cdot 32 \\
49 \cdot 07 \\
52 \cdot 62 \\
60 \cdot 90 \\
71 \cdot 20 \\
73 \cdot 50 \\
80 \cdot 14 \\
83 \cdot 85 \\
95 \cdot 59 \\
100 \cdot 34\end{array}$ \\
\hline
\end{tabular}




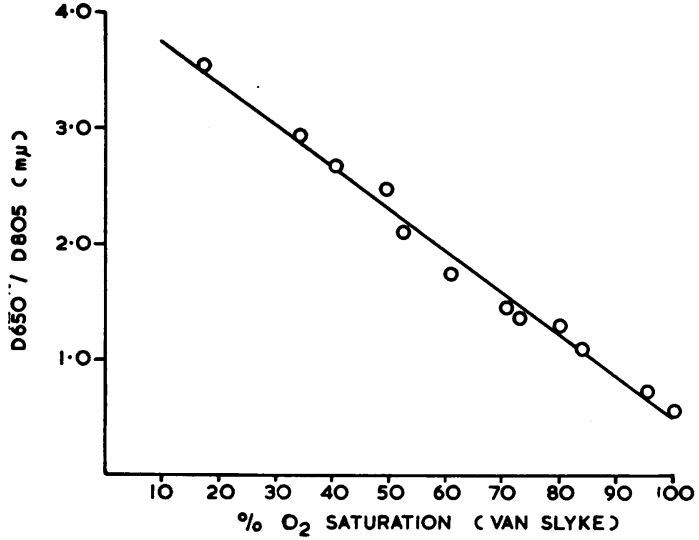

FIG. 2. Calibration curve between D650 and D805 and oxygen saturation determined by Van Slyke's method.

methods. The calibration curve and its $95 \%$ confidence limits were computed as the regression line of the spectrophotometer values on the Van Slyke values, the calculations being on the assumption that the Van Slyke estimates were correct. The maximum variation in duplicate values was 0.334 vol. $\%$ and compared well with the accuracy that Van Slyke (Peters and Van Slyke, 1932) suggests should be obtained $(0.25$ vol. $\%)$.

The correlation coefficient was calculated to be 0.995 and the regression line

$$
\mathrm{y}=0.9604 \mathrm{x}+3.5572 \text {. }
$$

Figure 2 shows a calibration curve between D650/ D805 and percentage oxygen saturation by Van Slyke's method, from which can be calculated the extinction coefficients of reduced and oxyhaemoglobin. The coefficients obtained in this way should agree with those determined by spectrophotometric means. The regression line can be calculated as

$$
y=-0.0359 x+4.095 \text {. }
$$

Substituting at two values of saturation and D650/ D805 the extinction coefficients can be calculated from the equation of Deibler et al. The calculated and known values agree to within $1 \%$. This provides an independent check of the method.

\section{DISCUSSION}

The method of Deibler et al. gave results that had a high degree of correlation with those obtained by Van Slyke's method after the initial difficulties had been overcome.
In agreement with other workers we found that the spectrophotometric method gave slightly highe values than the gasometric method. In our hands thi $\$$ variation was greatest between the 50 and $70 \%$ level? of saturation. A complete explanation for this finding is not available but a partial one may be that some of the samples came from patients with secondary polycythaemia due to chronic lung disease. Fot? example, in case 6 the haemoglobin was $130 \%$ and the error $6 \%$ as compared with the expected $3 \%-$ Normally only about $0.4 \%$ of the pigment of the red cell is present as methaemoglobin (Van Slyke, Hiller? Weisiger, and Cruz, 1946) but various authors have commented upon increases up to $5 \%$ in secondars polycythaemia. Normally the equilibrium haemos globin $\rightleftharpoons$ methaemoglobin is kept to the left bf reductive enzymes; when the haemoglobin mas? increases one might expect the capacity of the enzymes to be approached and the percentage of methaemoglobin increased. This leads on the one hand to overestimation of the oxygen capacity and or the other, due to absorption at $650 \mathrm{~m} \mu$, to a falsely high oxygen saturation by the spectrophotometrio method.

Bosman (1962) recalls two cases of toxic methaeब moglobinaemia with cyanosis and secondary poly: cythaemia in which gross discrepancies betweero spectrophotometric and gasometric saturations were observed.

When we became aware of this problem we made् one or two spot determinations of methaemoglobie which was usually greater than $2 \%$, but we werह unable to correlate the level with the degree oB secondary polycythaemia. To increase accuracy of blood oxygen determination beyond the levels. reported here would necessitate more detaile investigation of these pigments.

Our thanks are due to Dr. J. E. Cotes for his supervision and advice, to Mr. C. Rossiter for help with the results section, and to Dr. J. C. Gilson for his encouragement.

\section{REFERENCES}

Bosman, A. R. (1962). Personal communication.

Deibler, G. E., Holmes, M. S., Campbell, P. L., and Gans, J. (1959)م J. appl. Physiol., 14, 133.

Drabkin, D. L., and Austin, J. H. (1935). J. biol. Chem., 112, 105.

Hickam, J. B., and Frayser, R. (1949). Ibid., 180, 457.

Peters, J. P., and Van Slyke, D. D. (1932). Ouantitative ClinicafJ Chemistry, vol. 2, p. 321. Williams and Wilkins, Baltimore.

Van Slyke, D. D., Hiller, A., Weisiger, J. R., and Cruz, W. O. (1946) J. biol. Chem., 166, 121.

Wade, O. L., Bishop, J. M., Cumming, G., and Donald, K. W. (1953) Brit. med. J. 2, 902. 